\title{
The Mediating Role of Work-Family Enrichment Between Organizational Intervening and Organizational Citizenship Behavior: (Case Study: Banking Sector)
}

\author{
Hamid Reza Qasemi", Milad Behzadi \\ Department of Public Administration, Islamic Azad University, Arak Branch, Arak, Iran \\ Email address: \\ hamid-reza@myway.com (H. R. Qasemi),milad.55.behzadi@gmail.com (M. Behzadi) \\ ${ }^{*}$ Corresponding author
}

\section{To cite this article:}

Hamid Reza Qasemi, Milad Behzadi. The Mediating Role of Work-Family Enrichment Between Organizational Intervening and Organizational Citizenship Behavior: (Case Study: Banking Sector). Journal of Human Resource Management. Vol. 5, No. 1, 2017, pp. 1-11. doi: $10.11648 /$ j.jhrm.20170501.11

Received: December 26, 2016; Accepted: January 4, 2017; Published: January 28, 2017

\begin{abstract}
Work-life balance is a subject that due to changes in the environment, technology, demographics, and changes in individual expectations and demands, has attracted much attention of researchers and business leaders in the world. More recently, we can see that demographic changes in the number of women who work, and increase the number of families in which both women and men work, has created a lot of pressure on both men and women to manage their work and family issues. This study examines the mediating role of work-to-family enrichment between organizational intervening and organizational citizenship behavior variables in branches of Mellat Bank of Iran. This study in terms of objective is an applied research, and in terms of implementation approach is a causal research. Data collection tool in this study is a standard questionnaire with 28 questions. Cronbach's alpha and confirmatory factor analysis was used to determine the reliability and validity of the questionnaire which the amount of alpha obtained for the questionnaire demonstrated good reliability of tools, and values of factor loadings and $\mathrm{T}$ statistic obtained show the validity of the questionnaires. 300 questionnaires were collected among bank Mellat staff, and structural equation modeling statistical technique was used for data analysis. The results of study confirmed suggest the impact of organizational intervening variable on organizational citizenship behavior and work-to-family enrichment, but the effect of mediating role of work-to-family enrichment between organizational intervening variable on organizational citizenship behavior was not confirmed. Also, the impact of variables of work-family benefits and policies, work-family culture and management support was approved on organizational citizenship behavior, but the impact of occupational characteristics variable on organizational citizenship behavior was not confirmed. Also, the impact of occupational characteristics, and variable of work-family benefits and policies on work and family enrichment was confirmed. This despite the fact that the impact of work-family culture and management support variables on work-to-family enrichment was not confirmed.
\end{abstract}

Keywords: Work Enrichment, Organizational Citizenship Behavior, Organizational Intervening, Work-Family Culture

\section{Introduction}

Work-life balance is a subject that due to changes in the environment, technology, demographics, and changes in individual expectations and demands, has attracted much attention of researchers and business leaders in the world. More recently, we can see that demographic changes in the number of women who work, and increase the number of families in which both women and men work, has created a lot of pressure on both men and women to manage their work and family issues (Bharat, 2003; Rajadhyaksha, \& Bhatnagar, 2000; Komarraju, 1997; Sekaran, 1992).

Advances in technology have increased reliance on the Internet and use it. As a result, many employees work outside the office, which has led to blur the boundaries between work and family (Cooper, 1998). Environmental changes are evident in the increasing number of companies in the service sector, employees have to work longer, interact with 
customers frequently and operate in different time zones (NASSCOM, 2008). As a result, clear boundaries between work and family are fading. According to Hewitt study on the separation and retention of human resources in Asia and the Pacific, the need for work-personal life balance has become an essential element of employee expectations of employers. Work-life Balance has the effects on attitude, behavior, health, and organizational effectiveness as well. This has forced organizations to make changes which can help employees to manage the competitive demands between working life and family and at the same time, have productivity in the workplace (Eby et al., 2005).

Some of these changes are as follows: redesign jobs in order to create authority and provide more variety for employees (occupational characteristics), creating benefits and policies such as floating time (the life and work benefits and policies), providing social support (management support) and development of family friendly organizational culture (work family culture). Much research has shown positive benefits of such changes on the organizational citizenship behaviors (Kopelman et al., 2006). Of course, these results have been obtained in Western studies. Hence, in recent years, organizations have begun to make these changes to create a work - life balance of the employee (Poster, 2005). There are rich studies on work-life conflict, which have focused on work-family disproportion and their negative effects on the health of individual and organizational performance (Eby etal., 2005). More recently, researchers have tried to consider the positive effects of the common border between work and life, including work-family enrichment, a positive side effect, or family-life facilitation and synergy on individual attitudes and behavior (Greenhaus $\&$ Powell, 2006). Work-family enrichment is defined as "the amount that experience in a role improves the quality of life namely performance or affect on another role." Work-family enrichment is considered as one of the important aspects of work-life balance (Frone, 2003). This has focused on positive effects on family life (work enrichment for a family), and a positive impacts of family on working life (family enrichment for work). It is concluded that, there is a significant relationship between work enrichment for family and family enrichment for work with individual mental health, family performance and organizational citizenship behavior (Alice and Allis \& O’Driscoll, 2008). However, existing research on work-family enrichment are still limited to confirm these results. According to the concepts of work enrichment for the family, understanding the relationship between organizational changes for work-life balance and family enrichment for work is essential. As mentioned earlier, research indicates that organizational changes have a significant impact on organizational citizenship behavior. Research also shows that there is a significant relationship between organizational changes to create a work-family balance and work-family enrichment (Wayne et al., 2006).

Thus, the mediating role of work-family enrichment in the relationship between organizational interventions and organizational citizenship behavior is important, that has not been enough studied in research.

The main research question is: Does organizational intervening variable including (occupational characteristics, work-life benefits and policies, management support, work and family culture) with work-family enrichment intervening has a significant impact on the organized citizenship behavior or not?

Pathology related to lack of work-life balance of employees is important because a substantial portion of the fate of the organization, in terms of customer satisfaction, resources, success in the competition is determined by employees. In this regard, the primary responsibility of managers is not limited to manufacturing productivity and paying attention to organization's material resources. So that an effective management regardless of human factors and psychological needs of employees is not allowed.

Most of the personnel because of occupational characteristics and long working hours can't easily create balance between their work and family responsibilities (role of father, wife or mother). These conflicts interact on each other, stress and tension due to family problems can have a negative impact on job performance, (working life-family life conflict). At the same time, work stress will negatively affect an individual's personal and family life (working life - family life conflict) (Stewart and Brown, 2009).

If the organization is keen to focus more on retaining employees and increase their loyalty, and they make efforts for their organization rather than for themselves, the policies should be developed and commitment should be considered as a priority (Armstrang, 2009). Managers, particularly human resources managers of an organization can contribute significantly to staff to meet the aforementioned issues by providing work-life balance programs, as well as work-life balance and create more organized behavior in their employees.

Numerous studies in recent years have been done on worklife balance in the world, which shows the importance of the issue in scientific world. But the interesting point is that, little research has been done on work-life balance in Iranian organizations, and more research has been done in the American environment, and its results may not be generalized to the Eastern and Iranian environment. Therefore it is necessary that, first be reviewed according to Iranian culture, and secondly, be assessed in the domestic context. Work-family enrichment studies are still scarce, however, according to studies, we conclude that, in relationship between the organizational intervening to create balance between work and life-work consequences, workfamily enrichment is essential. As previously mentioned, the literature shows there is a positive relationship between the organizational intervening and organizational citizenship behavior. The literature shows there is a positive relationship between the organizational intervening to develop a work-life balance and work enrichment for family (Wayne et al., 2006). Thus, the estimation of the mediating role of work enrichment for family in the relationship between organizational intervening and organizational citizenship 
behavior is important that have not been addressed sufficiently in the literature.

Studies conducted in the organization, and interviews with directors and heads of the organization show that establishment of a balance between work and family life is difficult in the organization, and many employees because a lot of work responsibilities, and numerous family responsibilities can't easily create a balance between workfamily duties, therefore it causes problems in the workplace and inappropriate organizational citizenship behavior. Also, for other roles which they have, as a parent or spouse, it will be associated with problems. Therefore, we intend to measure variables such organizations and examine the impact of organizational interventions on organizational citizenship behavior.

\section{Theoretical Foundations and Literature}

Employees who have jobs with a specific job aspects, such as authority, variety, task identity, task significance and feedback, have experienced significant sense and have a sense of character development and motivation, and thus show more dependent on their organizations. More volume of control and monitoring of working conditions and scope of social interactions provide more opportunity to engage with extra-role behaviors or organizational citizenship behavior for staff.

Apart from job design to provide more flexibility and diversity, organizations provide more policies and working conditions to employees in order to help them manage work and family needs. Such changes are usually known as familyfriendly policies or benefits and work-life policies. Work-life benefits and policies include flexibility working conditions such as flexibility in planning to get to work or leave work, flexibility to select the workplace, leave for reasons of family issues, such as parental leave, direct financial assistance for child care and services, such as finding child care center for a new employee and so on. Individual and organizational benefits of such facilities include the reduction of Work-life conflict, and improving organizational citizenship behavior. Theoretically, work-life benefits and policies create a sense of confidence to the employees that their organization or employer support health and non-work needs of employees. According to organizational support and social exchange theory, sense of support has led to a more positive attitude to organization and employee increase his initiative participation because of the commitment sense which should make more benefits for additional benefits. We believe that, in employees in collectivistic such as India, they could expect in return for their loyalty, be supported on behalf of their organizations, and hence, when such support be taken from them, they may feel a commitment to the organization.

Official organizational supports, such as work-life politics and benefits, despite their reputation, may be not be important as much as to extent that the director of employee and organizational culture support work-life balance of employee (Thompson et al., 1999). Work-family culture is defined as "assumptions, beliefs and common values compared with the extant that the organization supports the integrity of working life and family of staff." Subsidiary work-family culture is created when people feel that are supported from employers in the balance between work and family roles, receive less working demands, and feel that the use of official support (e.g. leaving work in personal / family emergency) has fewer effects on their career path. According organizational support theory and the assumptions which based on them unwritten expectations and rules have more power in influencing attitudes and behavior toward written and formal rules, the research results show that work-family culture has a significant impact on organizational citizenship behavior. Supporting by a manager suggests understanding this issue by employee that whether direct supervisor is sensitive to his non-working problems or not. Direct supervisor can reduce the extent which the employee working role is disruptive for his family role by creating compliance of employee working role with his family obligations, such as allowing employees to leave the office to take care of her sick child or part-time work. Employees who believe that supervisors are supportive of their work-family issues have shown more organized citizenship behavior. According to social exchange theory, it is likely that employees have more citizenship behavior in exchange for support from their supervisors. However, extensive research shows that different aspects of occupational characteristics have a significant impact on work-family enrichment, as a positive side effect, and facilitating relationship between work and family, but the opposite results also exist. It is believed that intrinsic motivation factors, namely power, diversity, identity, importance and feedback have provided development experience and help to achieve energy and motivation, and assist in the acquisition of new skills and attitudes that can be transferred to facilitate better performance in the field of family.

These features when are in the occupational framework, can increase control over work-family issues, and makes the person be considered as an effective member of the organization and the effective member of the family. Authority has relationship with resources such as time management skill, initiative, and self-confidence, which if it depends on work in family activities and relationships, it seems to be in favor of work enrichment for the family. Diversity in job reduces negative impacts of poor quality of the role of parents on hardships. Low amount of freedom in decision-making, a measure that has both characteristics of the variety and the authority, is associated with low levels of work enrichment for the family.

The evidence gathered in the research indicates that, worklife benefits and policies had no significant effect on the conflict between work and life. Of course, the impact of work-life benefits and policies on work-family enrichment has rarely been studied (Hill, 2005, Wayne et al., 2006). This and colleagues found no evidence to confirm the significant 
effect assumed between the use of work-life benefits and policies on work and family enrichment, which necessitates further investigation. Theoretically, work-life benefits and policies should boost performance and productivity of staff, because they are useful in helping staff to manage the responsibilities of their work and family life. Since, employers provide less formal programs to support the family than employers in Western countries for their employees, it is interesting to discover that what is the role of such formal supports in improving the quality of life and work?. Work-family supportive culture enhances the mental of employees with increasing of approval and flexibility, which apparently has a positive impact compared to work. This sense of satisfaction when is transferred to the environment, may enhance the performance and health of the family, which indicates the possibility of work enrichment for the family. The research results refer to the potential significant impact of the work - family culture on work enrichment for the family.

Since management support for work-family enrichment is also important, supervisors can reduce the stresses of work that may potentially provide energy and confidence to participate in family activities.

First, it is concluded that the changes in work-life balance, such as occupational characteristics, work-life benefits and policies, supportive work-family culture and management support has a significant impact on some work-family enrichment criteria. Second, there is evidence to show that the work-family enrichment has a significant impact on organizational citizenship behavior. This evidence, along with the above-mentioned reasons, based on significant impact of organizational intervening on work-life balance and organizational citizenship behavior, refer to the possibility of mediation.

Researchers have examined the mediating role of perceived control and work-family conflict, to know whether the underlying processes have a significant impact on the work-life balance and organizational citizenship behavior changes or not, and found evidence confirming theories. Hence, work-family enrichment may increase the perceived control on work-family issues and reduce the negative effects of work-family conflict. It is probable that work-family enrichment may play mediating role between changes for work-life balance and occupational results.

Based on the demands and occupational resources framework, it is expected that the nature of occupational and supportive system in the working field to be considered as occupational resources, which is likely to increase the productivity and performance of employees in their family field. It is likely that individuals attribute an increase in their efficiency and performance to this field (e.g. working field) that has created this support. This refers to the possibility that, the effect of organizational resources spreads through the perceived work-family enrichment to the various spheres of life such as work and includes the attitudes and behaviors of employees at work. On the other hand, the belief that the effects of work-family changes on occupational attitudes and behavior may be due to effective performance in the work and family fields, is reasonable.

Social exchange theory says that employees are committed due to compensate organizational incentive supportive behaviors such as organizational citizenship behavior with greater participation in the organization. So, if there is workfamily enrichment feeling for organizational changes, such as enriched jobs, work-life benefits and policies, management support and family supportive culture, it is likely that, staff have the desire and motivation to organizational citizenship behavior. By integrating resources framework attitudes and occupational needs and social exchange theory, we expect that work-life balance supportive changes before promoting attitudes and behaviors such as organizational citizenship behavior create a sense of work-family enrichment. The above discussion specifies mediating role of work-family enrichment on the impact of organizational intervening on the work-family balance, and organizational citizenship behavior.

Ebrahimpur et al (2001) conducted a study on the subject of the relationship between occupational characteristics and organizational citizenship behavior in radio and television training center. In this study, occupational characteristics were evaluated according to Hackman and Oldham model and instead of individual and organizational results, OCB was considered. The research is descriptive and statistical study with population of 250 people.

Questionnaire was used for data collection and frequency and percentage statistical techniques and correlation coefficient were used to analyze the questions, confirm or reject hypotheses and to achieve the amount and intensity of the relationship between variables. The results showed that there was a significant positive relationship with job main dimensions and organizational citizenship behavior, between psychological main states and organizational citizenship behavior and between occupational characteristics and the two elements of organizational citizenship behavior and sensitive mental states.

Shahaei et al (2012) conducted a research on this subject. This study investigates the incentives and consequences of organizational citizenship behavior in SAPCO Co. With conceptualization and operationalization of organizational citizenship behavior in two dimensions of optional behaviors and beyond the job description toward coworkers and organizations and the selection of four incentives (in the context of social exchange theory) and an individual consequence, the conceptual framework of research was developed. Experimental results of this study showed that leader-follower exchange, perceived organizational support, violation of the psychological contract and occupational involvement, each of them leads to stimulate citizenship behaviors toward coworkers and the organization. In the meantime, violation of the psychological contract and occupational involvement didn't have any significant relationship with citizenship behavior toward coworkers. On the other hand, citizenship behavior toward organization has a significant negative impact on employees' turnover intentions. 
The results show that social exchange theory is a good framework to explain the incentives of organizational citizenship behaviors. However, this is slightly adjusted on a part of psychological contract. Also, doing or not citizenship behaviors toward coworkers and can't be a good symbol for predicting the probability of exit or retention of employees in the organization.

Iraji and Naghandar (2013) conducted a research on relationship with perceived organizational support and organizational citizenship behavior among the employees of Sport and Youth Organization in Mazandaran province. This study aimed to investigate the relationship between perceived organizational support with organizational citizenship behavior Directorate among the employees of Sport and Youth Organization in Mazandaran province. The population included employees of Sport and Youth Organization in Mazandaran province and the sample was considered equal to the population size. In order to collect data, two questionnaires of perceived organizational support Eisenberger et al (1986) and Oregon and Canucks organizational citizenship behavior (1996) were used. The validity of the questionnaire was determined using corrective comments of sport management experts, and reliability of both questionnaires was confirmed using Cronbach's alpha test. The method was correlation which has been implemented as field study.

In order to analyze the data, descriptive indicators, and Kolmogorov-Smirnov tests, Pearson correlation and regression analysis were used. The results showed that there is a positive and significant relationship between perceived organizational support and organizational citizenship behavior. The components of altruism, conscientiousness, sportsmanship, civic virtue and courtesy and consideration are significantly and positively associated with perceived organizational support. On the other hand, regression results show that perceived organizational support is able to predict all the components of organizational citizenship behavior.

Chen Chiu (2008) conducted a study on the integrated model of the relationship between management support and organizational citizenship behavior. This study extended previous studies by offering a comprehensive model through the underlying processes of the relationship between leadership support and organizational citizenship behavior. Data were taken from 323 employees and managers in seven Taiwanese companies. The results showed that the management support has a significant impact on organizational citizenship behavior d employees indirectly through cognitive processes (Person-organization fit and occupational satisfaction) and affective processes (stress).

Wang (2014) conducted a study on the subject of perceived management support and organizational citizenship behavior: the role of organizational commitment. This paper has examined relationship between perceived organizational support and organizational citizenship behavior and mediating role of organizational commitment. Also, the moderating role of organizational stress on the relationship between perceived organizational support and organizational commitment were studied. 238 samples were selected from Chinese employees. In order to study the moderating effect, the hierarchical regression was used. The results showed that whatever employees perceive greater support, show better citizenship behavior. Mediating role of organizational commitment was confirmed. In addition, the relationship between perceived organizational support and organizational commitment by moderating organizational stress becomes stronger.

According to the review, conceptual framework of the research is shown in figure 1 .

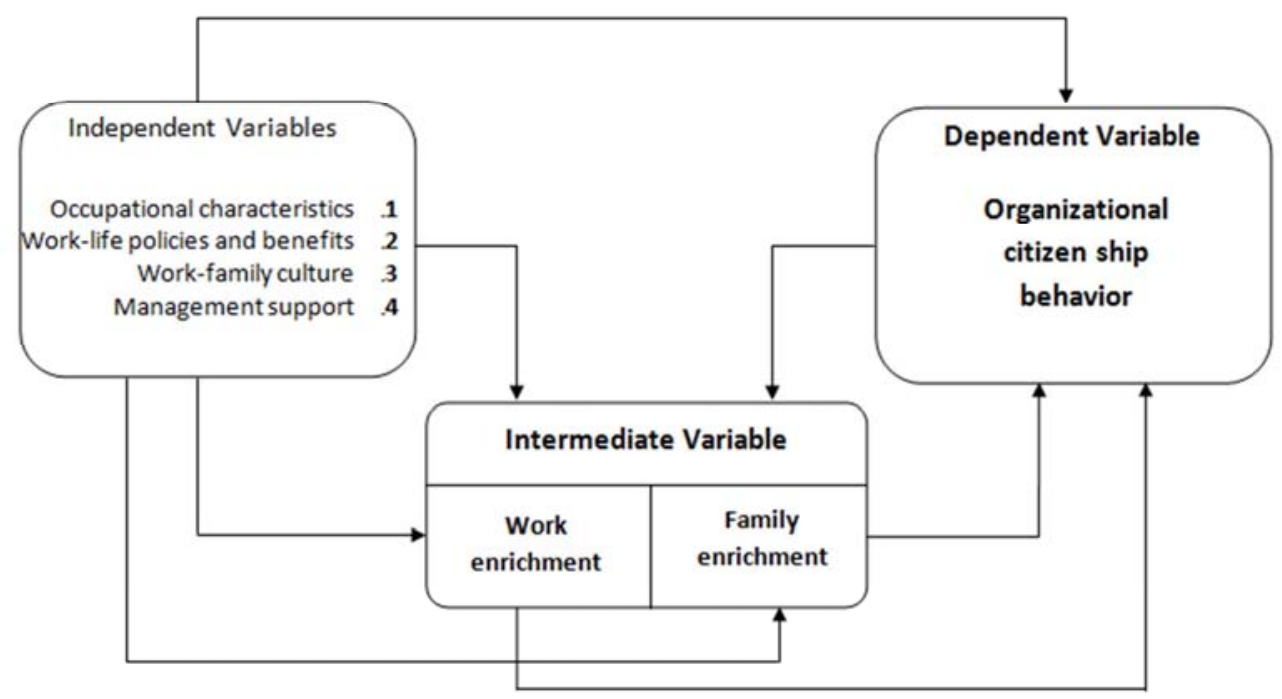

Figure 1. Conceptual Model of the Research.

According to the above model, the hypotheses are:

H1. Occupational characteristics have a significant impact on organizational citizenship behavior.
H2. Work-life Policies and benefits have a significant impact on organizational citizenship behavior.

H3. Work-family culture has a significant impact on 
organizational citizenship behavior.

H4. Management support has a significant impact on organizational citizenship behavior.

H5. Occupational characteristics have a significant impact on work-family enrichment.

H6. Work-life Policies and benefits have a significant impact on work-family enrichment.

H7. Work-family culture has a significant impact on workfamily enrichment.

H8. Management support has a significant impact on work-family enrichment.

H9. The mediating role of work-family enrichment has a significant impact on organizational intervening and organizational citizenship behavior.

\section{Research Methodology}

The present study in terms of objective is an applied study and with regard to how data collection (methodology) is a non-experimental method (field) and more accurately is considered as a descriptive method. The data collecting tool in the study was a questionnaire. The questionnaire consisted of two parts. The first part is related to measure the demographic variables and the second part is related to measure the research variables. The second part contains 28 questions that combination of questions and their extraction resources are visible in Table 1. All questions have been measured using the five-point Likert scale.

Table 1. Combination of the questionnaire and their extraction resources.

\begin{tabular}{lll}
\hline Variable name & Number of questions & Extraction Resource \\
\hline Occupational characteristics & 5 questions & Hackman and Oldham (1975) \\
Work-life benefits and policies & 8 questions & Thompson et al. (1999) \\
Work-family Culture & 3 questions & Lyness et al., (1999) \\
Management support & 3 questions & Caplan et al. (1975) \\
Work-family Enrichment & 3 questions & Carlson et al. (2006) \\
OCB & 6 questions & Lee and Allen (2002) \\
Occupational characteristics & 5 questions & Hackman and Oldham (1975) \\
Work-life benefits and policies & 8 questions & Thompson et al. (1999) \\
\hline
\end{tabular}

The population of the research included staff of the bank Mellet in the Markazi province. Population size was 370 people, according to the formula of the finite population (Morgan Table), the number of samples was 297 people. So because a sufficient number of samples to be collected and it shouldn't be less than 297, a total of 350 questionnaires were distributed using layer sampling method and finally 300 questionnaires were analyzed. Of the 350 questionnaires, 50 questionnaires were excluded because of the defect and inappropriate to respond.

In layer sampling, the ratio of different groups in the statistical population should be similar to proportions in the population statistics. It is essential that first the appropriate variable for layering, is selected. In this study, the degree of branches was used for layering. As mentioned above, the total number of branches of Bank Mellat branch is 15, how to combine the branches in terms of degree and also the number of questionnaires distributed and collected, are shown in Table 2. Table 3 also states the demographic characteristics of the study sample.

\subsection{Reliability and Validity}

Cronbach's alpha coefficient was used for reliability the value of this coefficient for the questionnaire was equal to 0.929, which indicates that the study has a good reliability. Also, reliability obtained for the occupational characteristics value is equal to 0.86 , for variable of work-life benefits and policies, it is equal to 0.89 , work-family culture, 0.73 , management support, 0.78 , work-family enrichment, 0.85 , organizational citizenship behavior, 0.91 . To determine the validity, confirmatory factor analysis was used. Based on confirmatory factor analysis, questions with the value of t-statistic greater than 1.96 are considered as significant questions and remained in the questionnaire (Casalo et al., 2000). As the results of the analysis can be seen in Table 3, all questions have been significant and have the values of significant $T$ Statistics and there is no need to remove any of them.

Table 2. Classification of the population according to Branch.

\begin{tabular}{lllll}
\hline Degree of branches & Number of branches & $\begin{array}{l}\text { Population to entire } \\
\text { population ratio\% }\end{array}$ & $\begin{array}{l}\text { The number of } \\
\text { questionnaires distributed }\end{array}$ & $\begin{array}{l}\text { The number of } \\
\text { questionnaires collected }\end{array}$ \\
\hline Grade 1 & 2 & $10 \%$ & $35=350 \times 10 \%$ & 30 \\
Grade 2 & $22 \%$ & $77=350 \times 22 \%$ & 63 \\
Grade 3 & $36 \%$ & $126=350 \times 36 \%$ & 110 \\
Grade 4 & 8 & $32 \%$ & $112=350 \times 32 \%$ & 97 \\
total & 7 & $100 \%$ & 350 & 300 \\
\hline
\end{tabular}

\subsection{Research Model Fitness}

Fitness is related to suitability and adequacy of the data for studying the model. This means that if fitness indexes indicate that the model fitness is good represents, data are adequate and good for analysis and to conclude on relationships in the model. In the past decade, several fitness tests are provided for structural equation models. Although 
various types of tests that are called "fitness indicators", are constantly compared, developed, but still there is no consensus even about an optimized test, and these indicators are classified in different ways have (Homan, 2005). Table 4 shows the fitting parameters.

Table 3. Results of Confirmatory factor analysis.

\begin{tabular}{|c|c|c|c|c|}
\hline Variable & Index & factor Loading & AVE & Cronbach alpha \\
\hline \multirow[t]{5}{*}{ Occupational characteristics } & $\mathrm{JC} 1$ & 0.69 & 0.564 & 0.863 \\
\hline & $\mathrm{JC} 2$ & 0.77 & & \\
\hline & $\mathrm{JC} 3$ & 0.73 & & \\
\hline & $\mathrm{JC} 4$ & 0.79 & & \\
\hline & JC5 & 0.77 & & \\
\hline \multirow[t]{8}{*}{ Work-life benefits and policies } & WLBP1 & 0.70 & 0.501 & 0.883 \\
\hline & WLBP2 & 0.70 & & \\
\hline & WLBP3 & 0.78 & & \\
\hline & WLBP4 & 0.70 & & \\
\hline & WLBP5 & 0.79 & & \\
\hline & WLBP6 & 0.81 & & \\
\hline & WLBP7 & 0.59 & & \\
\hline & WLBP8 & 0.53 & & \\
\hline \multirow[t]{3}{*}{ Work-family Culture } & WFC1 & 0.77 & 0.633 & 0.834 \\
\hline & WFC2 & 0.83 & & \\
\hline & WFC3 & 0.78 & & \\
\hline \multirow[t]{3}{*}{ Management support } & SS1 & 0.74 & 0.496 & 0.750 \\
\hline & SS2 & 0.70 & & \\
\hline & SS3 & 0.68 & & \\
\hline \multirow[t]{3}{*}{ Work-family Enrichment } & ENR1 & 0.80 & $656 / 0$ & $848 / 0$ \\
\hline & ENR2 & 0.89 & & \\
\hline & ENR3 & 0.074 & & \\
\hline \multirow[t]{6}{*}{ OCB } & OCB1 & 0.65 & 0.508 & 0.858 \\
\hline & OCB2 & 0.73 & & \\
\hline & OCB3 & 0.78 & & \\
\hline & OCB4 & 0.75 & & \\
\hline & OCB5 & 0.72 & & \\
\hline & OCB6 & 0.64 & & \\
\hline
\end{tabular}

Table 4. Fitting indicators.

\begin{tabular}{ll}
\hline $\mathbf{7 9 9 . 8 7}$ & Chi-Square \\
\hline 335 & df \\
2.38 & Chi-Square / df \\
0.068 & Root Mean Square Error of Approximation (RMSEA) \\
0.94 & Normed Fit Index (NFI) \\
0.90 & Non- Normed Fit Index (NNFI) \\
0.91 & Comparative Fit Index (CFI) \\
0.90 & Goodness of fit index (GFI) \\
0.85 & Adjusted Goodness of Fit Index (AGFI) \\
\hline
\end{tabular}

\section{Findings}

Pearson correlation test was used to investigate the relationship between variables. The correlation coefficient is a parameter method and is used for data with normal distribution or a large number of data. Before performing correlation test, using the Kolmogorov-Smirnov normality of the data will be discussed. Considering the fact that for all variables, the sig obtained for Kolmogorov-Smirnov test is more than $5 \%$, so assuming normal distribution of data is confirmed. In the correlation test, the null hypothesis and H1 hypothesis is as follows below. If significance level is less than 0.05 , the null hypothesis is rejected and the assumption of a confirmed.

$\mathrm{H} 0$ : correlation coefficient is zero (there is no significant correlation between the two variables).

$\mathrm{H} 1$ : correlation coefficient is not zero (there is a significant relationship between the two variables).

As the findings shows, there is a significant and positive relationship between all variables (Occupational characteristics, work-life benefits and policies, work-family culture, management support, work-family enrichment and OCB) positive correlation between the two there is. In the present study, the data obtained was analyzed using inferential statistics. The research method was descriptive, and statistical structural equation modeling technique (path analysis confirmed) was used. This means that, using the T-Student test examines significance of path coefficients between latent variables. In this study, a confidence level of .095 is considered (amount of $\alpha$ equal is considered equal to $5 \%$ ), Therefore, those hypothesized that have a positive path coefficients with the t-statistic greater than 1.96 are known as significant coefficients and related research hypothesis is confirmed. The results are shown in Tables 6 and 7. 
Table 5. Results of demographic variables.

\begin{tabular}{|c|c|c|}
\hline Variable & Frequency & Percent (\%) \\
\hline \multicolumn{3}{|l|}{ Sex } \\
\hline Man & 112 & $37.3 \%$ \\
\hline Female & 188 & $62.7 \%$ \\
\hline \multicolumn{3}{|l|}{ Age } \\
\hline 25 to 35 years & 120 & $40 \%$ \\
\hline 35 to 45 years & 105 & $35 \%$ \\
\hline More than 45 years & 75 & $25 \%$ \\
\hline \multicolumn{3}{|l|}{ Education } \\
\hline Diploma and Advanced Diploma & 97 & $32.3 \%$ \\
\hline Bachelor & 159 & $53 \%$ \\
\hline Master's degree or higher & 44 & $14.7 \%$ \\
\hline \multicolumn{3}{|l|}{ Work Experiences } \\
\hline Less than 10 years & 85 & $28.3 \%$ \\
\hline 11 to 20 years & 142 & $47.3 \%$ \\
\hline More than 21 years & 73 & $24.3 \%$ \\
\hline
\end{tabular}

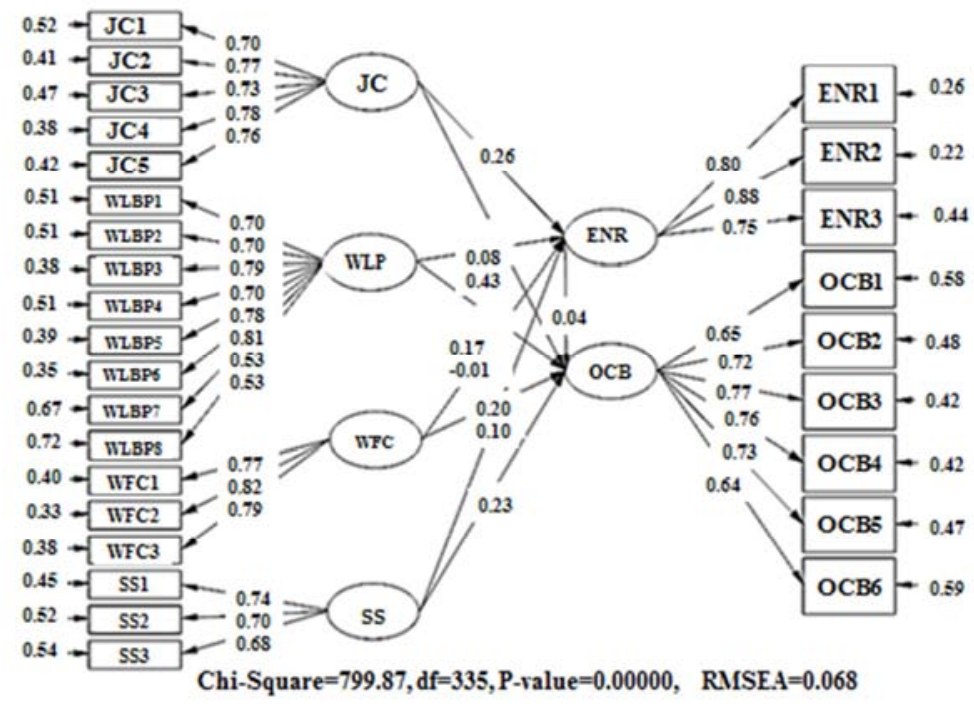

Figure 2. Values of factor loadings calculated by LISREL software.

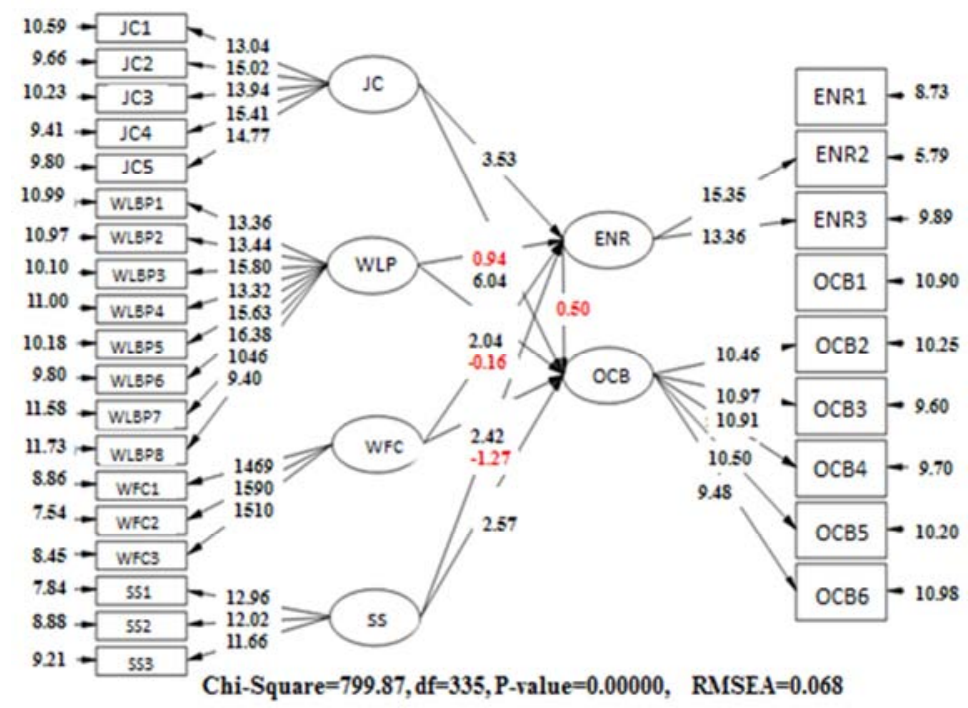

Figure 3. $t$-statistic values calculated by the LISREL software. 
Table 6. Results of hypotheses.

\begin{tabular}{llll}
\hline Hypothesis & Path Coefficients & Statistics & Results \\
\hline H1. & 0.08 & 0.94 & rejected \\
H2. & 0.17 & 2.04 & Confirmed \\
H3. & 0.20 & 2.42 & Confirmed \\
H4. & 0.23 & 2.57 & Confirmed \\
H5. & 0.26 & 3.53 & Confirmed \\
H6. & 0.43 & 6.04 & Confirmed \\
H7. & -0.01 & -0.16 & rejected \\
H8. & 0.10 & 1.27 & rejected \\
\hline
\end{tabular}

In order to study the effect of mediating role of workfamily enrichment between organizational intervening and organizational citizenship behavior, it is necessary that at first, the impact of the variables of organizational intervening on work-family enrichment, as well as the impact of work- family enrichment variable on organizational citizenship behavior examined to be examined, and if the effect of two relationships is confirmed and their path coefficient is multiplied by each other and if the number obtained is greater than Pearson path of two variables of organizational intervening on organizational citizenship behavior, the hypothesis is confirmed. Given that the amount of path coefficient which is obtained for two variables of workfamily enrichment on organizational citizenship behavior obtained is equal to -0.14 and t-statistic value is equal to 1.96 , so the significant effect of work-family enrichment variable on organizational citizenship behavior is not confirmed, so according to since the necessary conditions are not established, ninth hypothesis can't be confirmed. The following table summarizes the results of research ninth hypothesis.

Table 7. Result of the ninth hypothesis.

\begin{tabular}{lll}
\hline The main hypothesis of research & The impact & Significance \\
\hline The impact of organizational intervening on OCB & 71.0 & 5.86 \\
$\begin{array}{l}\text { The impact of organizational intervening on work-family enrichment } \\
\begin{array}{l}\text { The impact of mediating role of work-family enrichment between } \\
\text { organizational intervening and organizational citizenship behavior }\end{array}\end{array}$ & 0.68 & 9.61 \\
\hline
\end{tabular}

\section{Discussion and Conclusion}

Organizations are doing interventions to help their staff to manage the competing demands in career and family life to increase productivity in the workplace.

Such interventions generally are called as family-friendly work-life policies and benefits and policies. Work-life benefits and policies include flexible practices in work, and flexibility in selection of the workplace, flexibility in the adoption of absence due to staff family problems, such as taking care of elderly parents, direct financial assistance for child care, and information centers for issues such as finding day care for children of new staff.

Social exchange theory says that employees are committed due to compensate organizational incentive supportive behaviors such as organizational citizenship behavior with greater participation in the organization. So, if there is workfamily enrichment feeling for organizational changes, such as enriched jobs, work-life benefits and policies, management support and family supportive culture, it is likely that, staff have the desire and motivation to organizational citizenship behavior.

Based on the demands and occupational resources framework, it is expected that the nature of occupational and supportive system in the working field to be considered as occupational resources, which is likely to increase the productivity and performance of employees in their family field. It is likely that individuals attribute an increase in their efficiency and performance to this field (e.g. working field) that has created this support. This refers to the possibility that, the effect of organizational resources spreads through the perceived work-family enrichment to the various spheres of life such as work and includes the attitudes and behaviors of employees at work. On the other hand, the belief that the effects of work-family changes on occupational attitudes and behavior may be due to effective performance in the work and family fields, is reasonable.

\section{Conclusion}

Most of the personnel because of occupational characteristics and long working hours can't easily create balance between their work and family responsibilities (role of father, wife or mother). These conflicts interact on each other, stress and tension due to family problems can have a negative impact on job performance, (working life-family life conflict). At the same time, work stress will negatively affect an individual's personal and family life (working life - family life conflict).

If the organization is keen to focus more on retaining employees and increase their loyalty, and they make efforts for their organization rather than for themselves, the policies should be developed and commitment should be considered as a priority (Armstrong, 2009). Managers, particularly human resources managers of an organization can contribute significantly to staff to meet the aforementioned issues by providing work-life balance programs, as well as work-life balance and create more organized behavior in their employees.

Studies conducted in the organization, and interviews with directors and heads of the organization show that establishment of a balance between work and family life is difficult in the organization, and many employees because a lot of work responsibilities, and numerous family responsibilities can't easily create a balance between workfamily duties, therefore it causes problems in the workplace 
and inappropriate organizational citizenship behavior. Also, for other roles which they have, as a parent or spouse, it will be associated with problems.

Based on the results obtained, a number of suggestions are provided as follows:

1) It is recommended that employees participate in nonexecutive activities to improve the external image of organization.

2) It is recommended that employees raise issues they feel are useful for organizations, regardless of the risks and possible consequences.

3) It is recommended that employees contribute to new employees, without having to be asked, and always ready to assist and help their colleagues.

4) It is recommended that employees perform assigned tasks as soon as possible (e.g., providing information or reports, etc.).

5) It is recommended that managers create sufficient knowledge and skills to feel more satisfaction and become a better member of family.

6) It is recommended that managers create happiness in the employees' job to feel more satisfaction and become a better member of family.

7) It is recommended that managers create a sense of success and victory gained in the employees' job to feel more satisfaction and become a better member of family.

1so in line with the results, the following suggestions are provided for future researchers:

1) Since there are differences among the provinces and cities, carrying out similar studies in other provinces and other geographic areas and comparing the results with each other is recommended.

2) This study is a cross-sectional study. It is recommended that future researchers doing a longitudinal study examine the relationships among variables over time.

3 ) It is recommended that future researchers carry out this study for organizations in different regions due to cultural conditions prevailing in each region and compare the results with each other

4) It is recommended that future researchers examine other factors such as the role of education in the work-family interaction or the roe of career position work-family enrichment and the role of wages in organizational citizenship behavior

Also, the study has the following limitations:

1) This study like other survey-based research is exposed to the possibility that, replies have bias, so that, respondents answer questions considering their position or due to their personality characteristics and give their opinions in other form. And this issue is one of the limitations of this study. To achieve more accurate results and more sophisticated, it is recommended that further researchers instead of a questionnaire to collect data use more objective methods. Such as depth interviews or actual observation in the organization.

2) In the real world, researchers are faced with countless variables, which affect the phenomenon under study. Many of these variables are ignored when modeling. This is one of the research limitations.

3) This research is limited to a city, and may not apply for other cities. It would be considered as one of the Limitations.

4) Because of its inherent limitations in questionnaire, measuring variables by questionnaire is not very accurate. Therefore, how to measurement, and the use of questionnaires and surveys are considered as the limitations of the study, which researchers inevitably have considered it due to lack of access to objective assessment criteria.

5) This study was a cross-sectional study and it is considered as one of the limitations of this type of research which its results change over time results especially in statistical sector, which this can reduce the ability to generalize it.

\section{References}

[1] Armstrong, Michael, (2009). Handbook of human resource management practice, Eleventh Edition, Kogan Page Limited.

[2] Hooman, H., (2005). "Structural equation modeling using LISREL", SAMT publication, First edition.

[3] Allis, P. and O'Driscoll, M. (2008), "Positive effects of nonwork-to-work facilitation on well-being in work, family and personal domains", Journal of Managerial Psychology, Vol. 23 No. 3, pp. 273-91.

[4] Bharat, S. (2003), "Women, work, and family in urban India: towards new families?", in Berry, J. W., Mishra, R. C. and Tripathi, R. C. (Eds), Psychology in Human and Social Development: Lessons from Diverse Cultures, Sage, New Delhi, pp. 155-69.

[5] Cooper, C. L. (1998), "The changing nature of work", Community Work and Family, Vol. 1 No. 3, pp. 313-7.

[6] Casalo. L. V., Flavian, C. \& Guinaliu, M. (2008). "The role of satisfaction and website usability in developing customer loyalty and positive word-of-mouth in the e-banking services", The International Journal of Bank Marketing, 26 (6)‘pp.399-417.

[7] Eby, L. T., Casper, W. J., Lockwood, A., Bordeaux, C. and Brindley, A. (2005), "Work and family research in IO/OB: content analysis and review of the literature (1980-2002)", Journal of Vocational Behaviour, Vol. 66, pp. 124-97.

[8] Frone, M. R. (2003), "Work-family balance", in Quick, J. C. and Tetrick, L. E. (Eds), Handbook of Occupational Health Psychology, American Psychological Association, Washington, DC, pp. 143-62.

[9] Greenhaus, J. H. and Powell, G. (2006), "When work and family are allies: a theory of work-family enrichment", Academy of Management Review, Vol. 31, pp. 72-92.

[10] Hill, E. J. (2005), "Work-family facilitation and conflict, working fathers and mothers, work-family stressors and support", Journal of Family Issues, Vol. 26 No. 6, pp. 793819. 
[11] Komarraju, M. (1997), "The work-family interface in India", in Parasuraman, S. and Greenhaus, J. H. (Eds), Integrating Work and Family: Challenges for a Changing World, Quorum Books, Westport, CT, pp. 104-14.

[12] Kopelman, R. E., Prottas, D. J., Thompson, C. A. and Jahn, E. W. (2006), "A multi-level examination of work-life practices: is more always better?", Journal of Managerial Issues, Vol. 18, pp. 232-53.

[13] NASSCOM Newsline (2008a), IT-BPO Sector-Overview, available at: www.nasscom.in/Nasscom/ templates/NormalPage.aspx?id $1 / 454612$ (accessed 26 December 2008).

[14] Poster, W. R. (2005), "Three reasons for a transnational approach to work-life policy", in Kossek, E. E. and Lambert, S. J. (Eds), Work and Life Integration: Organizational, Cultural, and Individual Perspectives, Lawrence Erlbaum Associates, Mahwah, NJ, pp. 375-400.
[15] Rajadhyaksha, U. and Bhatnagar, D. (2000), "Life role salience: a study of dual career couples in the Indian context", Human Relations, Vol. 53, pp. 489-511.

[16] Sekaran, U. (1992), "Middle-class dual-earner families and their support systems in urban India", in Lewis, S., Izraeli, D. N. and Hootsmans, H. (Eds), Dual-Earner Families: International Perspectives, Sage, Newbury Park, CA, pp. 4661.

[17] Thompson, C., Beauvais, L. and Lyness, K. (1999), "When work-family benefits are not enough: the influence of workfamily culture on benefit utilization, organizational attachment, and work-family conflict", Journal of Vocational Behavior, Vol. 54 No. 3, pp. 392-415.

[18] Wayne, J. H., Randel, A. E. and Stevens, J. (2006), “The role of identity and work-family support in work-family enrichment and its work-related consequences", Journal of Vocational Behavior, Vol. 69 No. 3, pp. 445-61. 